\section{PHASE 2 STUDY OF FLX475 IN COMBINATION WITH IPILIMUMAB IN ADVANCED MELANOMA}

Rakesh Goyal*, Nicole Nasrah, Dan Johnson, William Ho. RAPT Therapeutics, South San Francisco, CA, USA

Background Regulatory $\mathrm{T}$ cells (Treg) can dampen antitumor immune responses in the tumor microenvironment (TME) and have been shown to correlate with poor clinical outcome. Translational studies have demonstrated an accumulation of Treg in tumors after treatment with immunotherapies including CAR-T cells and anti-CTLA-4, which could potentially reflect a mechanism of adaptive immune resistance. ${ }^{1-2}$ CCR4, the receptor for the chemokines CCL17 and CCL22, is the predominant chemokine receptor on human Treg and is responsible for the migration and accumulation of Treg in the TME. Preclinical studies with orally available CCR4 antagonists have demonstrated potent inhibition of Treg migration into tumors, an increase in the intratumoral Teff/Treg ratio, and antitumor efficacy as a single agent and in combination with checkpoint inhibitors, including anti-CTLA-4. ${ }^{3}$ In a firstin-human trial conducted in healthy volunteers, the oral CCR4 antagonist FLX475 was demonstrated to be well tolerated with outstanding pharmacokinetic and pharmacodynamic properties. ${ }^{4}$ An ongoing Phase $1 / 2$ clinical trial of FLX475 is examining the safety and preliminary antitumor activity of FLX475 as monotherapy and in combination with pembrolizumab in subjects with several types of advanced cancer. ${ }^{5}$ Given the preclinical data demonstrating a significant enhancement of the antitumor activity of anti-CTLA- 4 when combined with FLX475, a Phase 2 study investigating the combination of FLX475 and ipilimumab is now being conducted in subjects with advanced melanoma.

Methods This clinical trial is a Phase 2, multicenter, openlabel, single-arm study to determine the antitumor activity of FLX475 in combination with ipilimumab in subjects with advanced melanoma previously treated with an anti-PD-1 or anti-PD-L1 agent. The primary objectives of the study are to evaluate objective response rate, and the safety and tolerability of this combination. The study will first examine the safety of the combination of the $100 \mathrm{mg}$ PO QD recommended Phase 2 dose of FLX475 and the approved $3 \mathrm{mg} / \mathrm{kg}$ IV Q3W dose of ipilimumab as part of a safety run-in phase, prior to examining the degree of antitumor activity in approximately 20 subjects. Evidence of an overall response rate (ORR) notably greater than the expected ORR of ipilimumab monotherapy alone in such subjects, which has been shown to be approximately $14 \%,{ }^{6}$ would provide preliminary clinical evidence in support of the clinical hypothesis that CCR4 blockade by FLX475 can significantly enhance the antitumor activity of an anti-CTLA-4 checkpoint inhibitor.

Trial Registration ClinicalTrials.gov Identifier: NCT04894994

\section{REFERENCES}

1. O'Rourke D, Nasrallah M, Desai A, Melenhorst J, Mansfield K, Morrissette J, Martinez-Lage M, Brem S, Maloney E, Shen A, Isaacs R, Mohan S, Plesa G, Lacey S, Navenot J, Zheng Z, Levine B, Okada H, June C, Brogdon J, Maus M. A single dose of peripherally infused EGFRvIll-directed CAR T cells mediates antigen loss and induces adaptive resistance in patients with recurrent glioblastoma. Sci Trans/ Med 2017;9:eaaa0984. doi: 10.1126/scitranslmed.aaa0984.

2. Sharma A, Subudhi S, Blando J, Vence L, Wargo J, Allison JP, Ribas A, Sharma P. Anti-CTLA-4 immunotherapy does not deplete FOXP3+ regulatory T cells (Tregs) in human cancers-Response. Clin Cancer Res 2019;25:1233-1238.

3. Marshall L, Marubayashi S, Jorapur A, Jacobson S, Zibinsky M, Robles O, Hu D, Jackson J, Pookot D, Sanchez J, Brovarney M, Wadsworth A, Chian D, Wustrow D, Kassner P, Cutler G, Wong B, Brockstedt D, Talay O. Tumors establish resistance to immunotherapy by regulating Treg recruitment via CCR4. J Immunother Cancer 2020;8:e000764.

4. van Marle $S$, van Hoogdalem E, Johnson D, Okal A, Kassner P, Wustrow D, Ho W. Smith S. Pharmacokinetics, pharmacodynamics, and safety of FLX475, an orally-available, potent, and selective small-molecule antagonist of CCR4, in healthy volunteers. J Immunother Cancer 2018; 6(Suppl 1):P484(SITC 2018).

5. Powderly J, Chmielowski B, Brahmer J, Piha-Paul S, Bowyer S, LoRusso P, Catenacci $D$, Wu C, Barve $M$, Chisamore M, Nasrah N, Johnson D, Ho W. Phase I/II dose-escalation and expansion study of FLX475 alone and in combination with pembrolizumab in advanced cancer. Journal of Clinical Oncology 2020;38 (15_suppl): TPS3163 (ASCO 2020).

6. Long G, Mortier L, Schachter J, Middleton M, Neyns B, Sznol M, Zhou H, Ebbinghaus S, Ibrahim N, Arance A, Ribas A, Blank C and Robert C. Society for Melanoma Research 2016 Congress. Pigment Cell \& Melanoma Research 2017;30:76-156.

Ethics Approval This study has been approved by the Institutional Review Board at each investigational site.

http://dx.doi.org/10.1136/jitc-2021-SITC2021.548 